\title{
O desenvolvimento do letramento estatístico a partir do uso do Geogebra: um estudo com professores de matemática
}

\author{
The development of statistical literacy from use of Geogebra: a study with \\ teachers of mathematics
}

Cileda de Queiroz e Silva Coutinho

cileda@pucsp.br

Saddo Ag Almouloud

saddoag@pucsp.br

Maria José Ferreira da Silva

zeze@pucsp.br

\begin{abstract}
Resumo
Os conteúdos estatísticos para a escola básica são foco do presente artigo, particularmente a construção e interpretação de gráficos com uso do programa computacional Geogebra. O contexto da pesquisa foi a construção de um tutorial para professores desse nível de escolaridade, de forma que pudessem inserir o uso de tal ferramenta em suas aulas, visando favorecer o desenvolvimento do letramento estatístico por seus alunos. A coleta de dados deu-se por meio de observação participante e relatos dos participantes em diários de bordo, além da análise do produto final do projeto: o tutorial. Entre os resultados observados, cabe citar o grande envolvimento dos professores participantes da pesquisa na construção do tutorial, o fortalecimento das relações interpessoais, caracterizando o grupo colaborativo mas, principalmente, o aprofundamento dos conhecimentos específicos de conteúdo e dos conhecimentos didático-pedagógicos relativos a esses conteúdos.
\end{abstract}

Palavras-chave: Formação de professores. Representação gráfica. Geogebra. Transnumeração. Registros de Representação Semiótica.

\begin{abstract}
The central topic of this piece is the statistical content present at school, more specifically the construction and analysis of graphs using the computer program called Geogebra. The context of this research was the making of a tutorial for teachers so that they could include the use of such tool In: their classes to improve the development of statistical literacy by the students. The collection of data was made by present observation and reports from participants In: journals, as well as the analysis of the final product of this project: the tutorial. Amongst the given results are the huge involvement of the participant teachers In: the making of the tutorial, the strengthening of interpersonal relationships In: the group and, mostly, the deeper knowledge acquired of the specific content itself and the teaching aspects related to the same content.
\end{abstract}

Keywords: Teachers' education. Graphical representations. Geogebra. Transnumaration. Registers of Semiotic Representations 


\section{Introdução}

Os conteúdos relativos à estatística descritiva, introduzidos no currículo da Escola Básica desde a publicação dos Parâmetros Curriculares Nacionais (BRASIL, 1997, 1998, 2000), e os resultados das pesquisas mais atuais, convergem para a necessidade de se trabalhar simultaneamente a formação de professores (continuada e inicial) e a construção de conhecimentos pelos alunos. Gatusso (2006) aponta que as concepções dos professores de matemática sobre a estatística e o seu ensino, têm de merecer um maior interesse por parte dos responsáveis pela formação dos professores de matemática sob pena de que, mais tarde, quando estiverem trabalhando estes conteúdos na sala de aula, eles sejam desvalorizados. Destaca-se o papel fundamental do professor no desenvolvimento do raciocínio estatístico dos alunos pelas opções didáticas que realiza, pela mediação dos debates em aula, pelas trocas entre pares na resolução de problemas, entre outras situações, conforme assinala Carvalho (2003). A utilização de conceitos estatísticos no dia a dia pessoal e profissional das pessoas, subentende um nível de letramento ${ }^{1}$ minimamente funcional e, em alguns casos, de alfabetização científica, enquanto as pesquisas mostram que o ensino tem focado em um nível mais básico, chamado de cultural.

Pesquisas recentes desenvolvidas pelo grupo de pesquisa PEA-MAT, no contexto do projeto Processo de Ensino e Aprendizagem Envolvendo Raciocínio Estatístico e Probabilístico $(\text { PEA-ESTAT })^{2}$, que dialogaram com pesquisas nacionais e internacionais na área da Educação Estatística, comprovam o pouco ou nenhum conforto do professor para o trabalho com conteúdos dessa área de conhecimento. Dessa forma, resta a ele a concordância com o apresentado pelos livros didáticos e/ou materiais apostilados fornecidos por redes de ensino que, em sua maioria, centram as atividades nos cálculos matemáticos e na leitura de gráficos (entenda-se aqui "leitura dos eixos"). Identificou-se, nessas pesquisas, pouca exploração dos conceitos abordados, tal como indicam os resultados de Friolani (2007), Cardoso (2007), Bigattão (2007) e Silva (2007). Esta última autora salienta ainda a não capacidade para a percepção da variação na análise de um conjunto de dados, percepção essa que acreditamos ser a espinha dorsal da construção do raciocínio estatístico a partir de uma proposta de adaptação dos níveis propostos por Garfield (2002) para o contexto da apreensão da variabilidade.

\footnotetext{
${ }^{1}$ Os níveis de letramento estatístico que consideramos nessa pesquisa foram propostos por Shamos (1995).

${ }^{2}$ Desenvolvido de 2008 a 2010, sendo que contou com financiamento da FAPESP no último biênio.
} 
Vale destacar, que no cenário internacional aparecem trabalhos que se tornaram quadro teórico para a pesquisa em educação estatística, particularmente por sua importância na pesquisa ora apresentada: reflexões sobre o pensamento estatístico (WILD e PFANNKUCH, 1999), o letramento estatístico (GAL, 2002) e raciocínio estatístico (GARFIELD, 2002). Tudo isso, desenvolvido de forma a potencializar o desenvolvimento de habilidades para a análise exploratória de dados (BATANERO, ESTEPA, GODINO, 1991).

\section{Contextualização}

O presente artigo discute uma parte dos resultados do projeto de pesquisa PEA-ESTAT, particularmente a utilização de ambiente computacional como ferramenta didática para o desenvolvimento do letramento estatístico com professores de Matemática do terceiro e quarto ciclo do ensino fundamental ou do ensino médio. Utilizou-se, nessa fase do projeto, o programa Geogebra para a construção de gráficos estatísticos com características dinâmicas. Ele permite o trabalho com a escala dos eixos, a construção de mais de um gráfico no mesmo sistema de eixos, além da complementação dos gráficos com outras informações relevantes sobre as medidas-resumo do conjunto de dados em análise.

O objetivo de escolher geogebra foi discutir com estes professores as potencialidades de um ambiente dinâmico para a análise de gráficos estatísticos a partir da percepção da variação dos dados, já que a possibilidade de analisar simultaneamente mais de um gráfico, representando um mesmo banco de dados, potencializaria a percepção da variação dos dados, segundo resultados observados em Vieira (2008).

Dessa forma, reforçou-se a opção pela utilização da filosofia da Análise Exploratória de Dados como pano de fundo para o desenvolvimento do letramento estatístico. De acordo com Coutinho

Embora os professores, em suas declarações, pareçam concordar com a filosofia da Análise Exploratória de Dados, em suas práticas eles se restringem a um enfoque mais tecnicista, centrado no uso de algoritmos. [...] Do fato de termos escolhido esta filosofia como quadro teórico para o desenvolvimento dos trabalhos, o ponto mais importante não são os cálculos e construções, mas sim a análise dos dados pelo uso de representações múltiplas: tabelas, gráficos e medidas. O esforço deve ser concentrado para que os professores possam evoluir para o nível científico de letramento estatístico, de forma a que tenham autonomia na criação de situações de aprendizagem eficientes para o letramento de seus alunos dos diferentes níveis de escolaridade. (COUTINHO 2008, p. 5). 
Parte-se da hipótese de que o uso de ambiente computacional pode potencializar o desenvolvimento do pensamento estatístico, a partir da mobilização de mais de um registro de representação semiótica nos termos estudados por Coutinho, Silva e Almouloud (2011). Estes autores articulam a noção de transnumeração, proposta por Wild e Pfannkuch (1999) e Pfannkuch (2008), com a Teoria dos Registros de Representação Semiótica, proposta por Duval (2003).

Segundo Wild e Pfannkuch,

\begin{abstract}
A transnumeração perpassa todas as análises estatísticas de dados, ocorrendo cada vez que é mudada a maneira de observar os dados, com a esperança que isto conduza a um novo significado. É possível olhar mediante muitas representações gráficas para encontrar algumas realmente informativas. [...] ao final do processo, a transnumeração atua outra vez, quando descobertas representações de dados que ajudam a conduzir novas compreensões relativas ao sistema real de outras representações. (WILD; PFANNKUCH, 1999, p.5, tradução nossa).
\end{abstract}

No que se refere à Teoria dos Registros de Representação Semiótica, em uma leitura feita para sua aplicação na aprendizagem dos conteúdos estatísticos, Vieira (2008) afirma que:

[...] A resolução de problemas estatísticos passa não apenas pela transformação de um registro a outro, mas também pelo uso simultâneo desses diversos registros para obtenção do maior número de informações, permitindo a análise crítica dos dados, segundo os princípios da Análise Exploratória de Dados. (VIEIRA, 2008, p. 24).

Esta ideia é reforçada por Duval (2009), quando afirma que um registro de representação semiótica deve permitir o cumprimento de três atividades cognitivas:

- a construção de um traço ou ajuntamento de traços perceptíveis que sejam identificáveis como elemento de um sistema determinado (entendemos assim os gráficos estatísticos, as tabelas de distribuição e de distribuição de frequências e as medidas resumo como registros de representação semiótica);

- a transformação de uma representação em outra a partir das regras do sistema considerado (transformação de tabelas pela modificação do tipo de agrupamento dos dados, transformação dos gráficos pela modificação das escalas dos eixos, etc); 
- a conversão das representações produzidas em um sistema para representações de um outro sistema (conversão de tabelas em gráficos, tabelas em medidas, gráficos em medidas, e vice-versa).

O trabalho realizado partiu da necessidade percebida nos resultados das pesquisas, de que os professores em formação inicial e continuada precisam ter acesso a novas estratégias de ensino e abordagens diferenciadas dos conceitos de base dessa área do saber, a fim de ampliar seu leque de conhecimentos, pois somente assim poderão ter opção sustentada para mudar a prática docente. Com isso, as escolhas foram feitas de forma a construir situações de aprendizagem que favoreçam a utilização simultânea de mais de um registro de representação semiótica.

No que se refere à percepção da variabilidade em um conjunto de dados, há que se concordar com Cooper e Shore (2010), que sugerem:

[...] mais do que se introduzir métodos que quantificam variabilidade, os estudantes necessitam vivenciar experiências nas quais simplesmente comparam a variabilidade de conjuntos de dados com o propósito de desenvolver a compreensão e os insights do que variabilidade significa para diferentes tipos de dados. Comparações visuais da magnitude da variabilidade encoraja a discussão sobre o que faz um conjunto de dados mais ou menos variável, o que necessita a discussão sobre como a variabilidade se manifesta em um gráfico particular. (COOPER, SHORE, 2010, p.2, tradução nossa).

No que diz respeito à compreensão da variabilidade por professores, Sánchez, Silva e Coutinho (2011) apontam para a necessidade de pesquisas mais aprofundadas na área. Nesse contexto, se configura a questão da pesquisa aqui relatada: Qual a percepção da variabilidade de professores quando utilizam ambiente computacional para o trabalho com gráficos estatísticos com alunos do Ensino Fundamental II, a partir da articulação das noções de transnumeração e de registros de representação semiótica? 


\section{Metodologia e estratégias de atuação}

Serão discutidos neste tópico os seguintes pontos: a metodologia empregada e os procedimentos metodológicos (organização da equipe de pesquisa, estudos diagnósticos e coleta de dados, procedimentos empregados na formação dos professores).

O projeto partiu de uma proposta de pesquisa-ação, uma vez que o objetivo era ajudar os professores a determinar as condições de seu próprio trabalho e organizarem-se em comunidades de pesquisadores, dedicados a experiências emancipatórias para eles mesmos e para seus alunos, nos termos definidos por Kinhheloe (1997).

Participaram da pesquisa cinco professores de Matemática das séries finais do ensino fundamental e do ensino médio, interessados pelos problemas do ensino-aprendizagem da Estatística e que participavam do grupo de pesquisa como colaboradores. Destes, três haviam concluído o mestrado no Programa de Estudos Pós-graduados em Educação Matemática da PUC-SP.

Os encontros eram gravados e ocorriam todas as quintas-feiras, das $14 \mathrm{~h}$ às $17 \mathrm{~h}$, em um dos laboratórios de informática da Faculdade de Ciências Exatas e Tecnologias da PUC-SP. Além disso, periodicamente, os participantes redigiam um breve relato sobre seu desenvolvimento profissional e sobre a construção dos conhecimentos estatísticos em jogo. Dessa forma, foi composto o banco de dados relativo a esta fase da pesquisa. Ressalta-se que esta foi a última fase desenvolvida, e ocorreu após um ano de formação específica sobre conteúdos estatísticos (identificados a partir de questionário respondido pelos participantes). Um ano de trabalho coletivo no preparo de situações de aprendizagem sem uso de ambiente computacional. Estas situações foram levadas para sala de aula por um dos participantes, contando com a observação dos demais e discussões no grupo a cada sessão com os alunos (alunos de $6^{\circ}$ ano do Ensino Fundamental de uma escola da rede municipal de ensino, na cidade de São Paulo). Este professor voluntário para a aplicação das atividades não possuía mestrado, mas participava do grupo de pesquisa PEA-MAT e das formações continuadas oferecidas por esse grupo há dez anos.

A proposta de trabalho para essa última fase era a criação de um tutorial para construção de gráficos estatísticos com uso do programa Geogebra, sendo que este tutorial deveria ter linguagem acessível para qualquer professor que ensina matemática na Escola Básica. Os comandos deveriam manter o aspecto dinâmico da construção nesse ambiente, e também 
permitir a construção de mais de um gráfico no mesmo sistema de eixos, potencializando a comparabilidade para análise da variação dos dados.

Nenhum dos participantes conhecia essa funcionalidade do Geogebra, o que tornou a tarefa um desafio para todos e fortaleceu o aspecto colaborativo do grupo. Os participantes utilizavam o ambiente Moodle para comunicação fora das reuniões presenciais, além do fórum do Geogebra, o que permitia troca com pesquisadores de diversos países de língua portuguesa. Foram também trabalhados textos que traziam reflexões teóricas e resultados recentes de pesquisas sobre uso de ambiente computacional e sobre leituras de gráficos estatísticos.

\section{$O$ contexto da pesquisa na fase do uso do Geogebra}

Segundo Valente (1993), a mudança da função do computador como meio educacional, acontece juntamente com um questionamento da função da escola e do papel do professor. A verdadeira função desse aparato educacional não deve ser mais a de ensinar, mas sim a de criar condições de aprendizagem. Assim, o professor passa a ser o criador de ambientes de aprendizagem e o facilitador do processo de desenvolvimento intelectual do aluno. Tal observação reflete exatamente os objetivos da escolha feita neste estudo pela introdução de ambiente computacional na formação pretendida: uso de ambiente dinâmico que favorecesse a apreensão da variabilidade pelo uso simultâneo de mais de um registro de representação semiótica, com mobilização da transnumeração, conforme apresentado anteriormente no texto.

Segundo Valente (1993), se o objetivo principal do processo educativo é oportunizar o desenvolvimento da construção do conhecimento, com o aprendiz no centro do processo educativo compreendendo conceitos e reconhecendo a sua aplicabilidade em situações por ele vivenciadas, deve-se defender a utilização do computador como ferramenta, facilitando a descrição, reflexão e depuração de ideias.

Nesse âmbito, a análise das potencialidades do uso da informática, mais especificamente do Geogebra no ensino e aprendizagem da Estatística, e o fato de que um professor deve ter uma vivência expressiva com programas computacionais educacionais, antes de utilizá-los em sala de aula, justifica as escolhas feitas no momento do planejamento do projeto. Nestas condições, a formação de professores construída deveria abranger, também, conhecimentos de informática sobre os principais programas educacionais disponíveis e, ainda, discutir aspectos 
didáticos ligados ao uso dos mesmos em sala de aula. O professor deve saber que o computador e os programas educativos são ferramentas de trabalho, cujo uso precisa de uma estratégia didático pedagógica. É o professor quem deve definir essa estratégia em função dos objetivos do ensino e das ferramentas de que dispõe.

Um aspecto importante nessa fase do projeto foi o estudo das funcionalidades do Geogebra para construção de gráficos estatísticos, que tornou-se o foco principal das discussões ao longo dos encontros. Tais discussões eram sempre fundamentadas pela leitura de textos que tratavam do uso de ambientes computacionais, ou tratavam da compreensão e leitura de gráficos estatísticos.

O Geogebra é um programa de matemática dinâmica para ser utilizado nas escolas do Ensino Fundamental, Médio e Superior, que reúne geometria, álgebra, cálculo e estatística. Ele permite construir diversos gráficos estatísticos com uso de comandos diretos (disponíveis na caixa de comandos) ou construídos na linha de comandos.

O uso desse programa teve por objetivo, entre outros, responder uma das questões de pesquisa do projeto PEA-ESTAT: "Que contribuições para a formação dos conceitos relacionados ao Tratamento da Informação podem ser identificadas com o uso de ambiente informatizado?”. Para respondê-la, pelo menos parcialmente, parte-se das seguintes indagações: Quais as orientações para os alunos? Quais conhecimentos devem ser trabalhados e/ou mobilizados e qual o nível de escolaridade? Quantas sessões devem ser desenvolvidas com uso do programa Geogebra, para que este não se torne um distrator ${ }^{3}$ na construção dos conceitos visados?

Com o objetivo de elaborar um tutorial para a construção dos gráficos estatísticos com o Geogebra, foi utilizado um enfoque experimental, valorizando o envolvimento dos professores participantes, que deveriam construir seus conhecimentos específicos e didáticos para o trabalho com seus próprios alunos. Para isso, eles deveriam se envolver na construção do questionamento, no instrumento para coleta dos dados, na coleta efetiva dos dados e em sua representação gráfica.

No primeiro semestre de 2010, os encontros presenciais do grupo ocorreram nos dias 4, 11, 18, 25 de março; 8, 15, 22 e 29 de abril; 6, 1320 e 27 de maio; 10, 17 e 24 de junho; e 1 de julho. Encontros estes que foram utilizados para a familiarização com o software Geogebra e a preparação do tutorial (menos os dois primeiros, que foram usados para discutir e organizar

\footnotetext{
${ }^{3}$ Entendemos como elemento distrator aquele que faz com que o aluno mude o foco de atenção, dando à ferramenta um status de objeto de aprendizagem.
} 
os objetivos e metas a serem atingidas no semestre). Um dos encontros foi utilizado para discutir as limitações do Geogebra a partir da leitura e discussão de artigo científico sobre leituras de gráficos (BATANERO et all. 2009), e sobre o uso das diversas representações semióticas, bem como transnumeração, criando o desafio de buscar no Geogebra os recursos necessários para o bom desenvolvimento do pensamento estatístico. Buscou-se aprofundar o estudo já iniciado em Vieira (2008), ao assumir que, em estatística, a apreensão perceptiva de um gráfico permite identificar o que o gráfico representa e cada um de seus elementos. Além disso, os Níveis de Compreensão Gráfica, proposta por Friel, Curcio e Bright (2001), foram usados para analisar a compreensão gráfica mobilizada pelos sujeitos em situação de resolução de problemas propostos em contextos estatísticos.

Durante todo processo, a cada gráfico, a partir do qual se chegava a um conjunto de procedimentos que preservasse o aspecto dinâmico da construção ${ }^{4}$, o grupo discutia a abordagem didática: "em que o programa computacional contribui para a construção do pensamento estatístico? Como potencializar a percepção da variabilidade pelo uso do aspecto dinâmico? Quais os possíveis entraves?".

Diante de tais questionamentos, direcionamos a reflexão para o contexto que considerava o conhecimento dos alunos que participariam das atividades nos termos de Ball, Thames e Phelps (2008): conhecimento sobre os alunos, articulado com o conhecimento matemático do professor. A partir das contribuições do professor que iria aplicar as atividades elaboradas em sala de aula, foi possível não apenas discutir as linguagens e o roteiro do tutorial a ser construído, como também o tipo de tarefa a ser proposta para os alunos. Um exemplo dessa reflexão: o diagrama de setores, segundo testemunho do professor, provocaria um desvio da atenção dos alunos, dos aspectos relativos à análise dos dados representados para os aspectos técnicos da construção com o Geogebra, ou seja, estes aspectos técnicos se constituiriam em distratores para a aprendizagem visada. A Figura 1 ilustra uma das formas de construção desse gráfico no Geogebra, e as marcações no gráfico indicam a complexidade cognitiva de sua construção: a construção de cada um dos setores, em setores circulares consecutivos e interdependentes, de forma a manter o aspecto dinâmico.

\footnotetext{
${ }^{4}$ Buscava-se que a qualquer alteração na planilha de dados, o gráfico se atualizasse automaticamente, e vice-eversa.
} 
Figura 1 - Tela construída pelos professores para Diagrama de setores no Geogebra

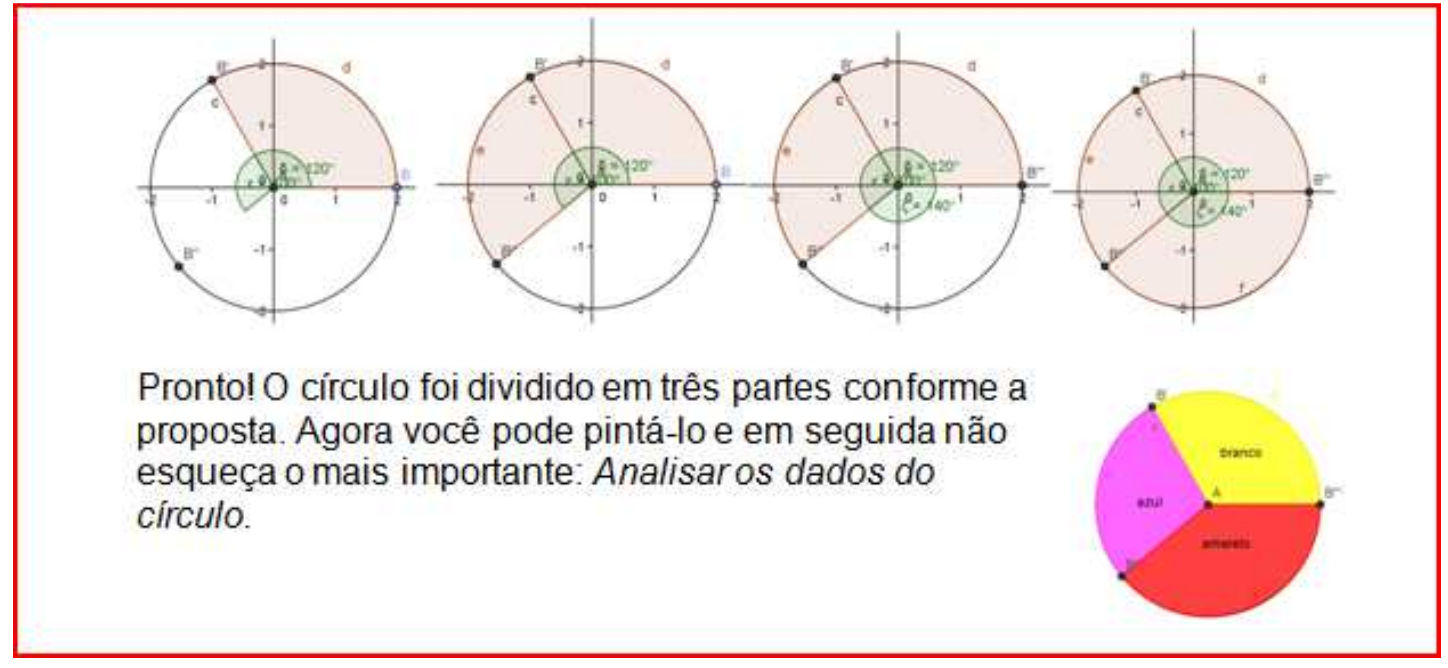

Fonte: os autores deste artigo.

A partir deste testemunho e das discussões desencadeadas por ele, tomou-se a decisão de que tal gráfico seria construído pelo professor e apresentado ao aluno, de forma que este pudesse perceber as consequências das mudanças no banco de dados analisado, e da comparação com os demais gráficos trabalhados simultaneamente. Por outro lado, o gráfico de setores poderia ser facilmente construído e analisado pelos próprios alunos de $6^{-}$ano do ensino fundamental, com uso de ferramentas não computacionais ou mesmo de planilhas eletrônicas, como o Calc ou Excel.

\section{Resultados observados}

Embora a construção do gráfico de setores no Geogebra tenha sido identificada como portadora de grandes dificuldades cognitivas, constatou-se que outros gráficos estatísticos tinham construção e manipulação bastante simples. Foi citado aqui a construção do gráfico de colunas e do box-plot no mesmo sistema de eixos, conforme o tutorial construído pelos professores.

O tutorial fornecido no site do Geogebra apresenta um conjunto de procedimentos para construção do gráfico de colunas e para a construção do box-plot sem, no entanto, tratar da construção de ambos no mesmo sistema de eixos para potencializar a comparabilidade. Dessa forma, a decisão pela construção de um novo tutorial mais adequado aos objetivos de aprendizagem pretendidos - entre eles, a apreensão da variabilidade em um conjunto de dados - foi unânime no grupo. Nesse processo de construção, optou-se por um conjunto de 
procedimentos para construção dos gráficos que utilizasse a localização das células no banco de dados como elemento do comando a ser digitado, ao invés de utilizar o valor assumido nessas células. Tal opção justifica-se pela possibilidade de alterar o banco de dados, produzindo a consequente atualização no gráfico construído.

Para os professores participantes, essa variável didática mostrou-se fundamental na construção de um cenário próprio à discussão da variabilidade, tal como proposto por Cooper e Shore (2010). As Figuras 2 e 3 ilustram um exemplo de alteração a partir da modificação de valores no banco de dados.

A utilização do Geogebra permitiu a alteração do banco de dados para que, sem a necessidade de nova digitação do comando, fosse modificado automaticamente o gráfico produzido. $\mathrm{Na}$ gestão do tempo didático, tal possibilidade é fundamental para a exploração das diversas formas que uma distribuição de dados pode assumir, ressaltando a concentração de dados ou a presença de dados discrepantes.

Os dois exemplos referem-se a dados sobre o número de páginas de jornais feitos em escolas. A partir da construção do primeiro gráfico, pelo comando DiagramaDeBarras[A2:A41, 0.5], onde A2:A41 é o intervalo de células considerado e 0.5 é a largura de cada uma das colunas, pôde-se obter, também, o segundo gráfico, conforme ilustrado na sequência.

Figura 2 - Primeira versão do gráfico de colunas construído para as células A2 a A41

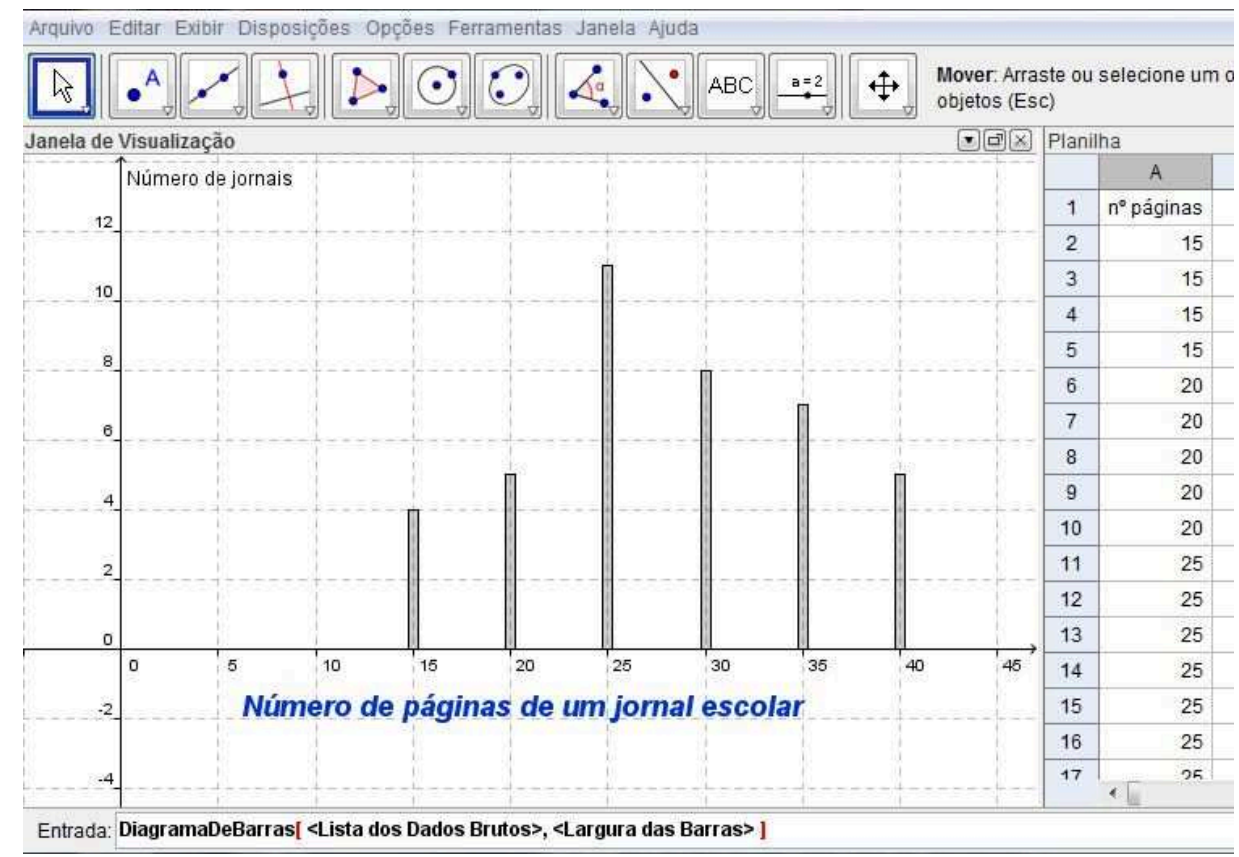

Fonte: os autores deste texto. 
Figura 3 - Segunda versão do gráfico de colunas construído para as células A2 a A41

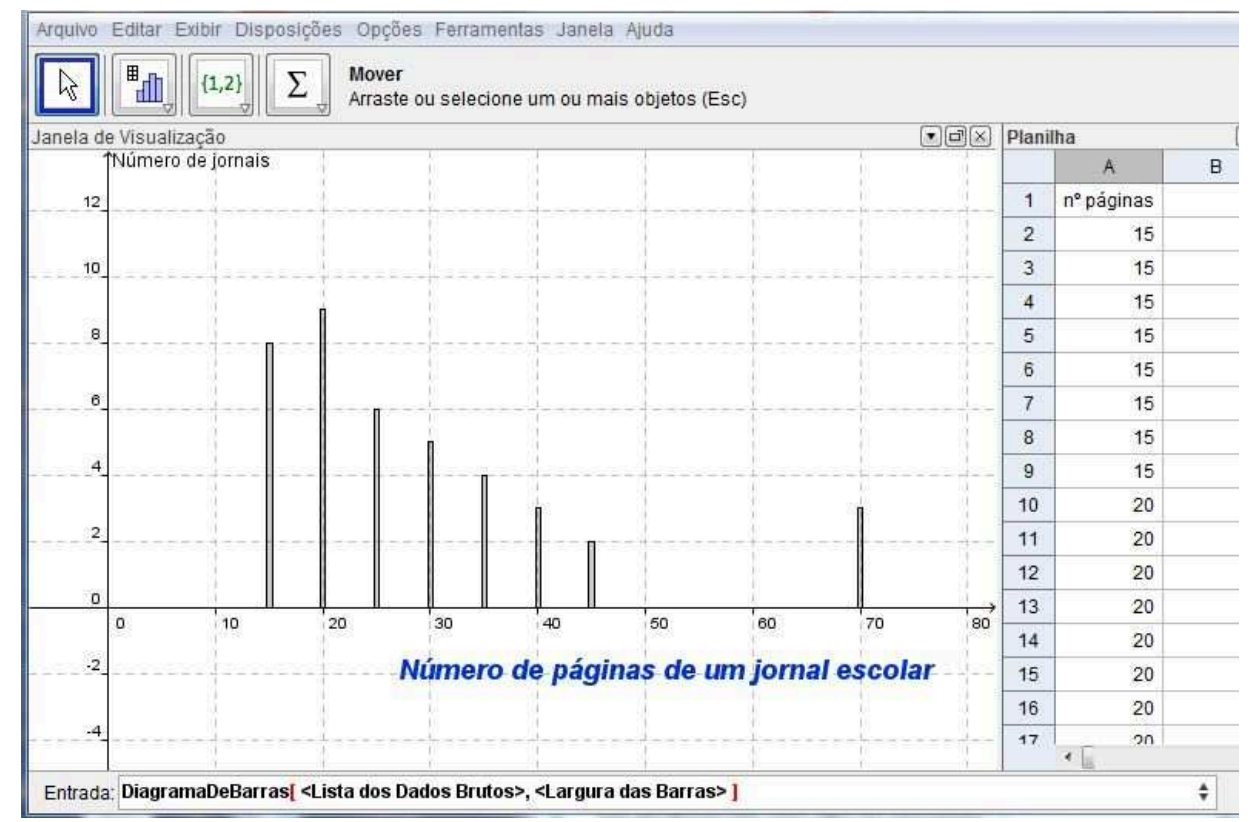

Fonte: os autores deste texto.

Nas discussões com o grupo de participantes, todos ressaltaram que tal procedimento na gestão da atividade não seria possível sem o uso de ambiente computacional. Destacaram, que os livros didáticos que costumavam utilizar não propiciavam esse tipo de discussão.

Os professores trabalhavam organizados em pequenos grupos, e cada vez que um desses grupos pensasse ter concluído a redação das instruções, todo o grupo de participantes validava os procedimentos ou dava novas sugestões a serem discutidas e validadas.

Apresentamos, na sequência, os procedimentos redigidos pelos professores (Figura 4) para a construção do gráfico de colunas e para a construção do gráfico de caixa (box-plot), conforme material utilizado em oficinas ministradas posteriormente pelo grupo em eventos de Educação Matemática (III SHIAM, 1ำ Seminário Internacional de Educação Matemática Secretaria Municipal de Educação da Cidade do Rio de Janeiro, Um dia de Reflexão - PEPG Educação Matemática da PUC-SP). 
Figura 4 - procedimentos redigidos pelos professores

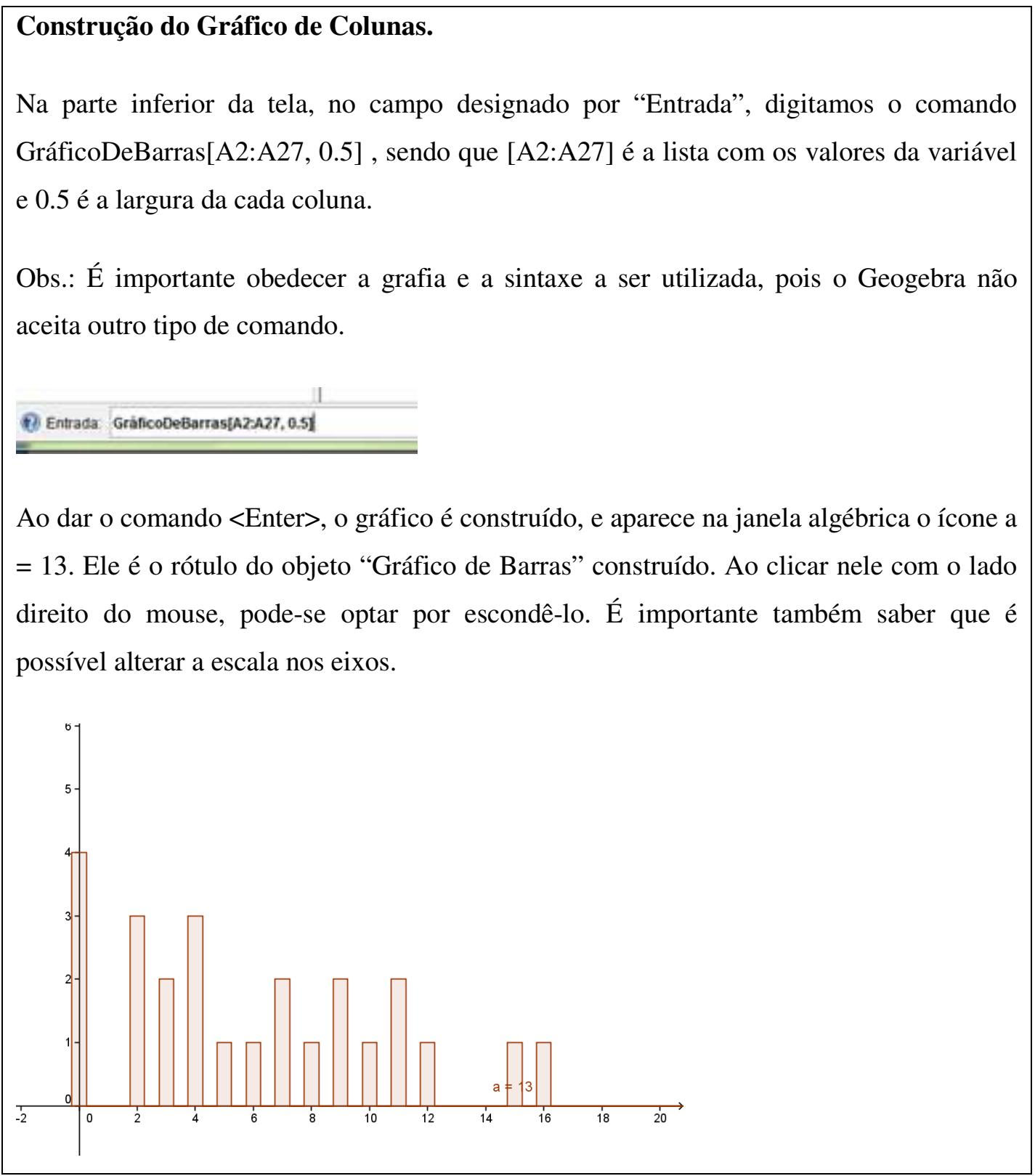

Fonte: tutorial construído pelos sujeitos da pesquisa.

A representação do gráfico de colunas pelo Geogebra provocou, em princípio, algumas dúvidas quanto à possibilidade de uso com alunos. Os professores discutiram o significado dos elementos que acompanham a construção do gráfico na janela algébrica, assim como o posicionamento das colunas no sistema de eixos, quando se solicita larguras maiores para elas. Com pode ser observado na Figura 5, os professores perceberam a necessidade de se fazer escolhas didáticas adequadas para o primeiro contato dos alunos com a construção, ou talvez, a possibilidade de, em um primeiro momento, o gráfico ser fornecido já construído, 
apenas para que os alunos manipulem o banco de dados e observem os efeitos na forma do gráfico. Assim, apreendendo o significado de variabilidade.

Figura 5 - procedimentos redigidos pelos professores

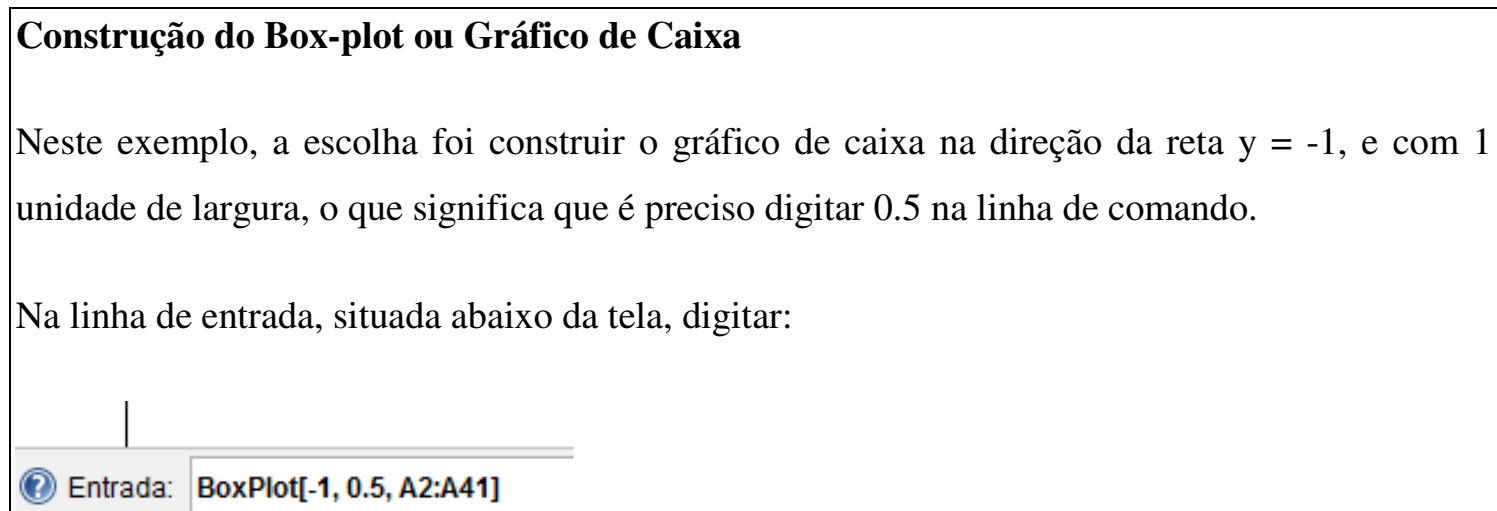

Neste exemplo, a escolha foi construir o gráfico de caixa na direção da reta y $=-1$, e com 1 unidade de largura, o que significa que é preciso digitar 0.5 na linha de comando.

Na linha de entrada, situada abaixo da tela, digitar:

Entrada: BoxPlot[-1, 0.5, A2:A41]

Neste comando, A2 e A41 delimitam o intervalo de células que contêm os dados ordenados, -1 a direção da reta $\mathrm{y}=-1$ sobre a qual será construído o gráfico, e 0.5 a metade da largura escolhida para a caixa (a escolha é arbitrária). Para a direção do gráfico de caixa, pode-se fornecer qualquer ponto do eixo vertical que pareça adequado, podendo-se também construir vários desses gráficos no mesmo sistema de eixos para facilitar a comparação. Por exemplo, pode-se construir um gráfico de caixa para cada classe que se tenha, contendo as notas dos alunos e, então, fazer a comparação entre as classes.

Observando o gráfico de caixas "mais de perto": repare que as linhas que unem a caixa aos extremos marcam a distância entre o valor mínimo observado e o primeiro quartil (Q1), e entre o valor máximo observado e o terceiro quartil (Q3). A linha no interior da caixa marca o valor da mediana, que é também o segundo quartil (Q2). A figura, dessa forma, está dividida em quatro regiões, que representam os quatro conjuntos nos quais o conjunto original foi dividido, ou seja, quatro regiões com o mesmo número de elementos.

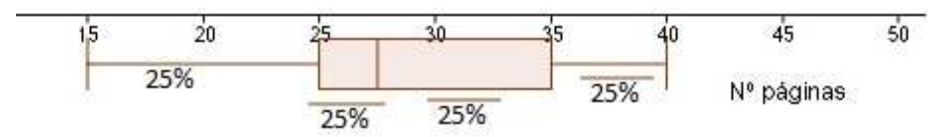

Nessas condições, o que se observa nesse gráfico é a densidade de cada subconjunto, e não o número de elementos: quanto menor o comprimento relacionado à parte observada, maior é a concentração dos dados em seu interior.

Fonte: tutorial construído pelos sujeitos da pesquisa. 
Apesar do fato de nunca terem trabalhado em sala de aula com esse tipo de gráfico, a discussão para a inclusão no tutorial a ser construído foi bastante rica, uma vez que todos concordavam com a possibilidade de seu uso, graças a pouca complexidade cognitiva presente em sua construção e interpretação. Os resultados observados por Garcia (2008) e por Canossa (2008) incentivavam tais reflexões: "se os alunos observados pela Fernanda (Garcia) puderam não apenas construir, mas explicar aos colegas os significados do que construíram, então é possível trabalhar com esse gráfico”. Quanto aos resultados observados por Canossa (2008), os comentários eram: “O professor resiste, pois não conhece o gráfico. Reparem que quando ele viu do que se tratava, quando o Canossa explicou, ele aceitou, mas ainda ficou resistente..." Tal comentário refere-se ao fato do professor colaborador que participou das atividades propostas por esse autor, mesmo após trabalhar com o gráfico com uso do software Fathom, ter preferido utilizar com seus alunos apenas o gráfico de colunas. Já os alunos observados por Garcia (2008), que eram de uma turma de $6^{\circ}$ ano do ensino fundamental, construíram o significado para as informações obtidas pela leitura do gráfico Box-plot, sem a necessidade de intervenções da professora: apenas as informações contidas nas instruções para construção foram suficientes para a compreensão da concentração dos pontos em cada intervalo representado.

A análise dos procedimentos e comentários tecidos pelos professores reforça a importância da visualização de gráficos, pois ela permite aprofundar a descrição da variação dos dados (apreensão perceptiva) e, dessa forma, passar da simples leitura dos eixos (leitura dos dados) para leitura além dos dados, nos termos de Friel, Curcio e Bright (2001). Além disso, ela auxilia na mobilização do conhecimento sobre distribuição de dados, simetria, amplitude, que permitem ao sujeito a apreensão da variabilidade. Tal mobilização também é favorecida pela apreensão dos quartos (conjuntos definidos pelos quartis, ilustrados no box-plot). A construção no mesmo sistema de eixos permite que, ao se modificar o banco de dados na planilha, ambos os gráficos se atualizem automaticamente. A modificação da escala nos eixos também atualiza automaticamente os dois gráficos. Estes dois aspectos servem como entraves para a simples leitura de eixos, obrigando o aluno a avançar no nível de leitura de gráficos nos termos de Friel, Curcio e Bright (2001), e por consequência, no nível de letramento estatístico, nos termos de Shamos (1995).

Este avanço pode ser justificado pela apreensão operatória da figura constituída pelo conjunto de gráficos apresentados (no caso, gráfico de colunas e box-plot, construídos pelo Geogebra em um mesmo sistema de eixos), tal como proposto por Vieira (2008) e ilustrado na Figura 6. 
Figura 6 - Gráfico de colunas e Box-plot construídos no mesmo sistema de eixos do Geogebra

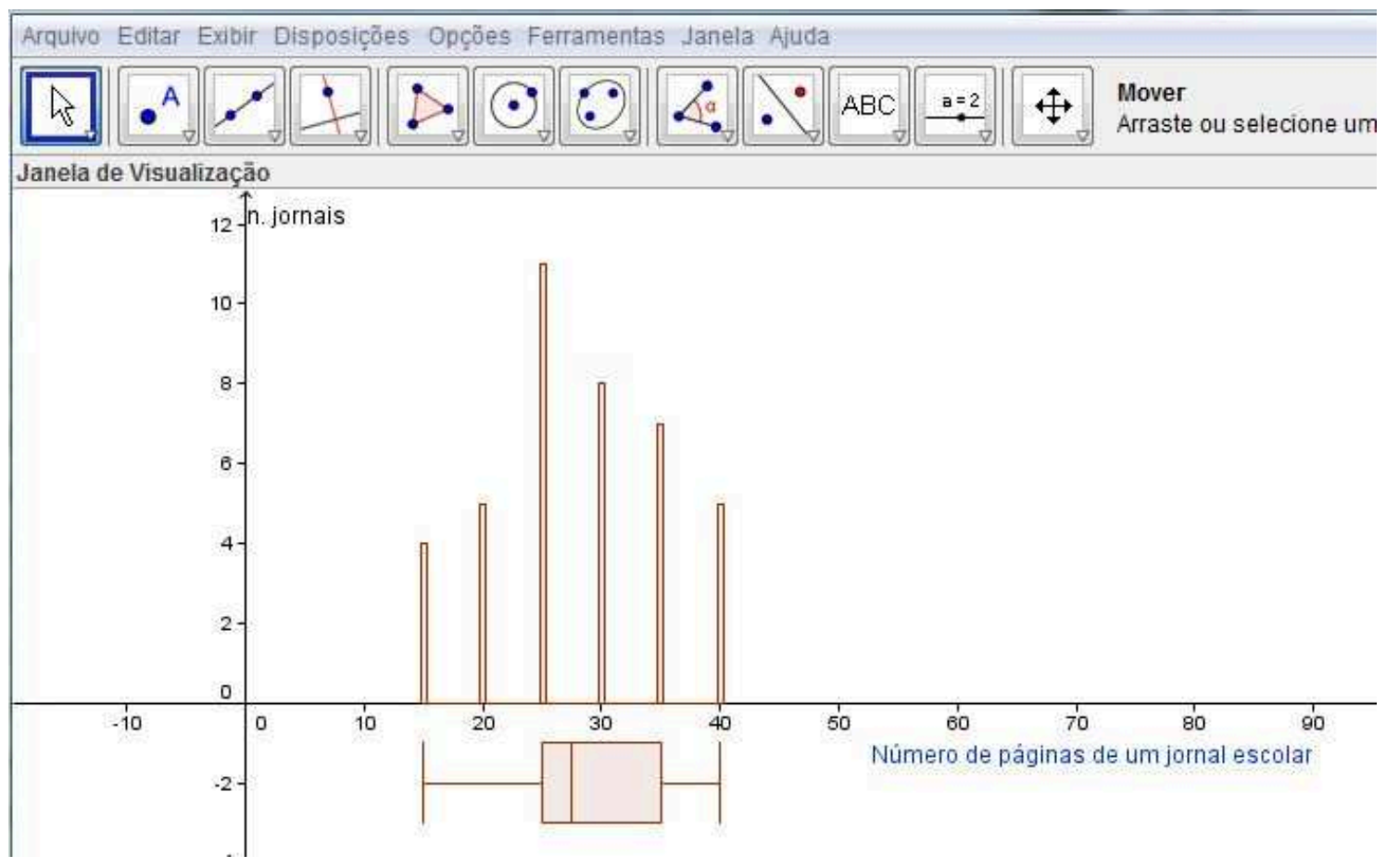

Fonte: os autores deste texto

Alguns aspectos que indicam similaridades entre a ideia de transnumeração e a de conversão de registros de representação semiótica foram discutidos em Coutinho, Silva e Almouloud (2011), e identificados na análise dos encontros com os professores participantes, no que se refere à construção de seus conhecimentos específicos e didáticos: as discussões envolviam a mobilização dos conhecimentos estatísticos para a redação das orientações para construção dos gráficos, mas também o conhecimento didático, pois a cada conjunto de instruções redigido, a discussão se voltava para o aluno.

\section{Conclusões e perspectivas}

Foi destacado o papel fundamental do professor no desenvolvimento do raciocínio estatístico dos alunos, nas opções didáticas que realiza, na mediação dos debates em aula, nas trocas entre pares na resolução de problemas, entre outras situações, conforme assinala Carvalho (2003).

Um dos fundamentos teóricos da pesquisa foi o nível de letramento estatístico, nos termos definidos por Shamos (1995) e apresentados em Gal (2002). A utilização de conceitos estatísticos no dia a dia pessoal e profissional das pessoas subentende um nível de letramento 
minimamente funcional e, em alguns casos, letramento científico, enquanto as pesquisas mostram que o ensino tem focado em um nível mais básico, chamado cultural.

Uma dificuldade didática do professor, como pode ser observado nos diferentes depoimentos dos participantes do presente projeto, é criar uma apresentação adequada do tema em estudo, que possibilite ao aluno desempenhar um papel ativo na aprendizagem, isto é, o de desenvolver um trabalho autônomo. O trabalho do professor é complexo, pois além de fazer funcionar o cenário construído para essa aprendizagem, ele precisa mobilizar não apenas seus conhecimentos específicos, mas também os didáticos, conhecimentos sobre os alunos e sobre o contexto, nos termos de Ball, Thames e Phelps (2008).

Avaliando os resultados observados nesse projeto, no que tange a formação de professor, pôde-se constatar que uma parte dos objetivos propostos no projeto PEA-ESTAT foram alcançados, particularmente no que se refere ao uso de ambiente computacional para desenvolvimento do letramento estatístico, pois existem indícios de que o trabalho realizado contribuiu para:

- a formação de professores, quanto ao conhecimento de conceitos estatísticos e metodológicos que são utilizados para a construção de tal conhecimento e o conhecimento didático do conteúdo;

- a construção de uma predisposição para explorar situações-problema, procurar regularidades, fazer conjecturas, fazer induções, pensar de maneira lógica;

- o aumento da confiança pessoal em desenvolver atividades cujo objetivo é a construção de conhecimentos/saberes estatísticos e em usar diferentes procedimentos para resolver problemas.

Nesse aspecto, a análise global do projeto permite destacar o papel fundamental do grupo colaborativo no desenvolvimento profissional dos professores participantes: não apenas os professores em formação, mas também os professores que participaram como colaboradores e pesquisadores. Criou-se, assim, um grupo colaborativo agindo sobre o ensino e a aprendizagem dos conteúdos da estatística, buscando interferir e interferindo efetivamente nas comunidades de prática dos professores de Matemática de suas respectivas escolas. Ressaltouse, durante todo o tempo do projeto, que o tempo de desenvolvimento não pode ser limitado a um curto período de intervenção e assessoramento desses professores: o processo é longo e contínuo. Foi possível observar que o tempo de participação no projeto não foi suficiente para 
a construção da efetiva autonomia dos participantes. A troca de experiências e conhecimentos específicos sobre suas escolas, sobre seus alunos, sobre os contextos de trabalho se mostraram e se mostram fundamentais para a construção e desenvolvimento conceitual (conhecimentos nos termos anunciados por Ball, Thames e Phelps (2008)).

Apesar do final do projeto em termos de financiamento FAPESP, o conjunto de dados é tão denso que ainda estão em análise para organização do livro proposto no projeto inicial. Por esta razão, a pretensão é avançar nas análises do banco de dados constituído ao longo do projeto, visando novas pesquisas.

\section{Referências}

ARTEAGA, P.; BATANERO, C.; DIAZ, C.; CONTRERAS, J. M. El lenguage de los gráficos estadísticos. Revista Iberoamericana de Educación Matemática, n. 18, p. 93-104, 2009.

BALL, D. L.; THAMES, M. H.; PHELPS, G. C. Content Knowledge for Teaching: What Makes It Special? Journal of Teacher Education, 59(5), p. 389-407, 2008.

BATANERO, C.; ESTEPA, A.; GODINO, J. D. Análisis exploratorio de datos: sus posibilidades en la enseñanza secundaria. Suma, 9, p. 25-31, 1991. Disponível em $<$ http://www.ugr.es/ batanero/publicaciones\%20index.htm>. Acesso em março de 2009.

BIGATtão JR., P. A. Concepção do Professor de Matemática sobre o Ensino da Estatística. Dissertação de mestrado, PUC-SP, 2007. http://www.pucsp.br/pos/edmat.

BRASIL. MINISTÉRIO DA EDUCAÇÃO / Secretaria de Educação Fundamental. Parâmetros Curriculares Nacionais 3: Matemática ( $1^{\mathrm{a}}$ a $4^{\mathrm{a}}$ séries). Brasília: MEC/SEF, 1997.

BRASIL, MINISTÉRIO DA EDUCAÇÃO / Secretaria de Educação Fundamental. Parâmetros Curriculares Nacionais. Brasília: MEC/SEF. 1998. Volume: Matemática.

CANOSSA, R. A Estatística no Ensino Médio: uma sequência didática trabalhada com professores. Dissertação de Mestrado- PUC-SP. 2009. <http://www.pucsp.br/pos/edmat>.

CARDOSO, R. O professor de matemática e a análise exploratória de dados no ensino médio. Dissertação de mestrado, PUC-SP, 2007. <http://www.pucsp.br/pos/edmat>. 
CARVALHO, C. Aceitar o desafio de ouvir os alunos: O exemplo da estatística. In: CIEFCUL (Ed.). Itinerários Investigar em Educação, p. 537-546, 2003. Lisboa: Centro de Investigação em Educação da FCUL. Disponível em $<$ http://cie.fc.ul.pt/membros/ccarvalho/index.htm>. Acesso em 5 de julho de 2007.

COOPER, L. L.; SHORE, F. S. The effects of data and graph type on concepts and visualizations of variability. Journal of Statistics Education. v. 18, n. 2, 2010. Disponível em <http://www.amstat.org/publications/jse/v18n2/cooper.pdf $>$.

COUTINHO, C. Q. S. Teaching Statistics In: Elementary and High School and Teacher Training. In: BATANERO, C.; BURRILL, G.; READING, C.; ROSSMAN, A. (Eds). Joint ICMI/IASE Study: Teaching Statistics in School Mathematics. Challenges for Teaching and Teacher Education. Proceedings of the ICMI Study 18 and 2008 IASE Round Table Conference. Disponível em <http://www.ugr.es/ icmi/iase_study/>. Acesso em 19/10/2011.

COUTINHO, C. Q. S; SilvA, M. J. F.; AG ALMOUloud, S. Desenvolvimento do Pensamento Estatístico e sua articulação com a Mobilização de Registros de Representação Semiótica. Bolema, v. 24, n. 39, p. 495-514, 2011.

DUVAL, R. Registros de representação semiótica e funcionamento cognitivo da compreensão em matemática. In: MACHADO, S. D. A. (org.). Aprendizagem em Matemática: Registros de representação semiótica, p. 11-33. Campinas, SP: Papirus, 2003.

DUVAL, R. Semiósis e pensamento humano - registros semióticos e aprendizagens intelectuais. Tradução de LEVY, L. F.; SILVEIRA, M. R. São Paulo: Editora Livraria da Física, 2009. (fascículo 1).

FRIEL, S. N.; CURCIO, F.; BRIGHT, G. W. Making sense of graphs: critical factors influencing comprehension and instructional implications. Journal for Research in Mathematics Education, 32(2), p. 124-158, 2001.

FRIOLANI, L. C. O pensamento estocástico nos livros didáticos do ensino fundamental. Dissertação de mestrado. PUC-SP. 2007. <http://www.pucsp.br/pos/edmat>.

GAL, I. Adults' statistical literacy: meanings, components, responsibilities. International Statistical Revew, 70(1), p. 1-50, 2002.

GARCIA, F. de M. A abordagem das medidas de posição e a percepção da variabilidade em um conjunto de dados com alunos do Ensino Fundamental II. Dissertação (Mestrado em Educação Matemática) - PUC-SP, 2008. <http://www.pucsp.br/pos/edmat>.

GARFIELD, J. The Challenge of Developing Statistical Reasoning. Journal of Statistics Education, v. 10, n. 3, 2002. <http://www.amstat.org/publications/jse/v10n3/garfield.html> Acesso em 5 de julho de 2007.

GATTUSO, L. Statistics and Mathematics. Is it possible to create fruitful links? In: ROSSMAN, A.; CHANGE, B. (Eds). Proceedings of the Seventh International Conference on Teaching Statistics. CD ROM. Salvador (Bahia): IASE and ISI. 2006. 
KINCHELOE, J. L. A formação do professor como compromisso político. Mapeando o pós-moderno. Porto Alegre: Artes Médicas, 1997.

PFANNKUCH, M. Training teachers to develop statistical thinkin. In: BATANERO, C.; BURRIL, G.; READING C.; ROSSMAN, A. (Eds). Joint ICMI/IASE Study: teaching statistics in school mathematics. Challenges for teaching and teacher education, 18th, 2008. Proceedings..., 2008. Disponível em <http://www.ugr.es/ icmi/iase_study/>.

SANCHEZ, E.; SILVA, C.B.; COUTINHO, C. Teachers' understanding of variation. In: BATANERO, C.; BURRILl, G.; READING, C. (Eds). Teaching Statistics in School Mathematics - challenges for teaching and teacher education. International Commission on Mathematical Instruction. Springer, p. 211-222, 2011.

SHAMOS, M. H. The myth of scientific literacy. New Brunswick: Rutgers University Press, 1995.

SILVA, C. B. Pensamento Estatístico e raciocínio sobre variação: um estudo com Professores de Matemática. Tese de doutorado. PUC-SP, 2007. $<$ http://www.pucsp.br/pos/edmat $>$.

VALENTE, J. A. Diferentes usos do computador na Educação, In: VALENTE, J. A. (org.), Computadores e conhecimento, repensando a Educação. UNICAMP-NIED, p. 1-23, 1993.

VIEIRA, M. Análise Exploratória de dados: Uma abordagem com alunos do Ensino Médio, Dissertação de Mestrado, PUC-SP, 2008. <http://www.pucsp.br/pos/edmat>.

WILD, C. J.; PFANNKUCH, M. Statistical thinking in empirical enquiry. International Statistical Review, Auckland, v. 67, n. 3, p. 223-265. 1999. 